\title{
CONTRASTE DE LAS FORMAS PRONOMINALES DE TRATAMIENTO EN ESPAÑOL Y CHINO. ASPECTOS SOCIOCULTURALES Y PRAGMÁTICOS Y SU DIDÁCTICA EN EL AULA DE E/LE (CHINA) ${ }^{1}$
}

\author{
YANG SONG ${ }^{2}$ \\ Universidad de Pekín \\ JINWEI WANG
}

Universidad de Estudios Extranjeros de Pekín

\begin{abstract}
Resumen
Mediante el presente artículo pretendemos contrastar las formas pronominales de tratamiento en español y en chino abordando aspectos socioculturales y pragmáticos concretos. Asimismo, deseamos que nuestras conclusiones supongan una contribución para el trabajo de aula de E/LE en China. Se revisan los trabajos previamente realizados relativos al tema para concretar su situación actual; se compila un corpus a partir de tres teleseries y se analiza el manual de español más utilizado en este país para descubrir los principales problemas existentes.
\end{abstract}

Palabras clave: formas pronominales de tratamiento, sociocultural, pragmática, didáctica

\begin{abstract}
In this article, we intend to contrast the pronominal forms used in Spanish and Chinese while covering the pragmatic and sociocultural aspects. In addition, we expect that the conclusions we provided ending up being an efficient contribution to the Spanish as a second language in China. The finished assignments related with the topic are previously revised, a corpus is compiled through the three TV series and the most used Spanish manual in that country is analyzed in order to find out the main existing problems.
\end{abstract}

Key words: pronominal forms of address, sociocultural, pragmatic, didactic

\section{INTRODUCCIÓN}

A partir de los años sesenta, fecha en la que se inició la investigación sociolingüística, los investigadores han venido defendiendo la estrecha relación existente entre la lengua y los sistemas sociales. Mediante sucesivos trabajos, se ha

\footnotetext{
${ }^{1}$ Debemos dar las gracias a D. Juan Carlos Manzanares Triquet y a D. Nicolás Giménez Doblas por su ayuda en la revisión gramatical del artículo, así como a los expertos que han participado en la evaluación por su corrección de estilo.

${ }^{2}$ Universidad de Pekín (China). Correo: yang.song@pku.edu.cn; wangjinwei@bfsu.edu.cn. Recibido: 03-05-2015. Aceptado: 11-06-2015.
} 
ido conformando un enfoque epistemológico que concibe la lengua como un reflejo de la estructura social. Uno de los aspectos por los que los lingüistas han mostrado más interés ha sido el de las formas pronominales de tratamiento (en adelante, FPT), dado que su uso parece estar condicionado por los diferentes elementos que conforman el sistema social. Estas formas, como define la Nueva Gramática de la Lengua Española (I: 1250), son "variantes pronominales que se eligen para dirigirse a alguien en función de la relación social que existe entre el emisor y el receptor". En este sentido, las FPT en español son $t \dot{u}$, vosotros/as, usted/es, vos, etc., mientras que en chino son 你 (tú), 你们 (vosotros/as), 您 (usted), 您们 (ustedes) ${ }^{3}$, etc. El estudio de las FPT supone, desde el principio, un tema clásico para los sociolingüistas, ya que constituye uno de los aspectos de la estructura gramatical de muchas lenguas con mayores y más perceptibles implicaciones sociales. En otras palabras, la existencia de dos formas diferentes para señalar a una segunda persona muestra cómo los procesos interactivos de la sociedad se reflejan en la lengua, y viceversa, cómo el uso lingüístico constituye un modo de acción social.

El estudio pionero de este campo fue The prounouns of power and solidarity, realizado por Brown y Gilman en 1960. Basado en los conceptos de poder y solidaridad, presentes en todas las relaciones sociales, inició una vía de investigación y estableció un marco general para el estudio de las fórmulas de tratamiento que ha sido aplicado a diversas lenguas por parte de numerosos investigadores. No obstante, a lo largo de la trayectoria investigadora de este campo, la investigación de las FPT no se ha limitado solo al aspecto sociolingüístico, sino que se ha llevado a cabo también desde otras disciplinas y perspectivas: gramática, sociología, pragmática, historiografía lingüística y, cómo no, la didáctica de lenguas extranjeras.

Se han elegido las FPT como objeto de estudio debido a que es esencial tener en cuenta su correcta utilización como un elemento clave para establecer el contexto interactivo adecuado entre quienes intervienen en el proceso comunicativo. Es decir, el uso adecuado de las FPT favorece la comunicación, mientras que su uso inadecuado puede provocar incomodidad en el interlocutor.

Sin embargo, la adecuación no se acepta del mismo modo en todas las lenguas ni en todas sus variedades. Este trabajo pretende realizar un estudio contrastivo de las FPT en español y en chino desde el punto de vista de la pragmática y el componente sociocultural -en concreto, la comparación de los valores pragmáticos de las FPT, así como su distribuciónen distintosámbitos-, teniendoencuenta las posiblesinterferencias lingüísticas que se producen cuando entran en contacto dos sistemas diferentes, con el propósito de conocer las diferencias y semejanzas pragmáticas y socioculturales que hay entre los dos idiomas. A partir de ahí, se analiza la didáctica de las FPT, en lo que a estos aspectos se refiere, en el manual de español más usado en China. La ventaja de optar por una visión contrastiva unida a una visión multidisciplinar de aprendizaje de las FPT es la de poder entender el mecanismo de la transferencia lingüística no como un

\footnotetext{
${ }^{3}$ Cabe mencionar que estas formas son las que se utilizan en el putonghua de China, la variedad lingüística oficial de este país asiático, dejando de lado las múltiples formas de sus otras lenguas y dialectos. Para más información, véase Song (2011).
} 
acto mecánico, sino como un fenómeno de carácter cognitivo, que exige comparación y reflexión por parte de los alumnos sobre los distintos sistemas.

\section{ESTUDIOS ANTECEDENTES}

El trabajo pionero en este campo, como ya se ha mencionado, fue realizado por Brown y Gilman. En él formularon su conocido marco de análisis de los pronombres de segunda persona de las lenguas europeas distinguiendo entre dos dimensiones semánticas, denominadas como la dimensión del poder y la dimensión de la solidaridad. Para ellos, poder designa el control que unas personas ejercen (o pueden ejercer) sobre otras en una determinada situación interactiva: "one person may be said to have power over another in the degree that he is able to control the behavior of the other" (Brown y Gilman, 1960: 255). A partir de esta aseveración, dedujeron que la presencia del poder en la comunicación verbal requiere de un trato asimétrico: "power is a relationship between at least two persons, and it is nonreciprocal in the sense that both cannot have power in the same area of behavior" (ibíd.). El poder, según ellos, trae consigo la elección de diferentes formas según la jerarquía relativa de los interlocutores. Es decir, el superior emplea formas $T^{4}$ cuando se dirige al inferior y el inferior le contesta en forma $V$. Los factores que promueven en el inferior la utilización de $V$ con el superior son, por ejemplo, la riqueza, la fuerza física, la edad, el sexo, el rol social o familiar, así como otros papeles que los hablantes asumen en situaciones con diferencias de jerarquía.

Al contrario del poder, la solidaridad "comes into the European pronouns as a means of differentiating address among power equals" (Brown y Gilman, 1960: 258). La solidaridad introduce "a second dimension into the semantic system on the level of power equivalents" (ibíd.). En la dimensión de la solidaridad, los interlocutores emplean recíprocamente $T$, pero también pueden emplear $V$ si no tienen una relación estrecha (aunque estén en un mismo nivel); este último es el denominado uso simétrico de $V$.

No obstante, aunque los sistemas del poder y la solidaridad parecían haber sido al principio aceptados por buena parte de los investigadores, cada vez se encuentran más contraejemplos. Por un lado, sobre el tratamiento simétrico $(T-T, V-V)$ y el asimétrico ( $T$ $V, V-T)$ basados en la teoría de dimensión horizontal y vertical, hay otros investigadores que no creen que se correspondan exactamente con la actualidad ni con la realidad, como por ejemplo, el tuteo frecuente al profesor, tanto en la enseñanza secundaria como en la universitaria. Otro ejemplo de infracción sería el tuteo practicado de forma usual, en hospitales y residencias de ancianos, por los enfermeros y personal médico. Como opina Rodríguez Mendoza (2003: 73), el modelo de Brown y Gilman está “inscrito en la lingüística sistémica y basado en la reciprocidad $(T-T, V-V) /$ no reciprocidad $(T-V$, $V-T)^{\prime}$, lo que "no es suficiente para explicar la variabilidad observada en el uso de los tratamientos en las distintas lenguas y culturas".

\footnotetext{
${ }^{4}$ En este tipo de estudios, ya es bastante común marcar $T$ a tú, vosotros/as o 你, 你们 $\mathrm{y} V$ a usted/es, 您,
} 您们. 
Por otro lado, respecto a las etiquetas de poder y solidaridad, se ha observado que no todos los casos encajan en estos sistemas. Blas Arroyo (1994: 388-389), por ejemplo, dice que "ni el poder ni la solidaridad son factores estáticos que determinan mecánicamente un tratamiento categórico", ya que puede ocurrir por diversas razones que "un locutor que ocupa un nivel jerárquicamente superior al de otro y del que recibe la forma $V$ devuelva esa misma forma de tratamiento y no $T$, como podría esperarse de una aplicación mecánica del sistema interpelativo". Fernández (2007: 8), por su parte, considera que el eje semántico poder/solidaridad ha sido muy discutido en revisiones posteriores, y lo mismo podría ocurrir con cualquier otro par que los sustituya, como confianza/formalidad. Destaca que "no parece nada fácil asignar a cada uno de estos pronombres un único valor en el sistema sin asumir a cambio un exceso de contraejemplos" (ibíd.), de ahí que multiplique el número de etiquetas, pues queda una gran variedad de situaciones para las que ninguna de las anteriores propuestas sería adecuada. Si bien la Real Academia Española en su Nueva gramática de la lengua española mantiene la distinción tradicional entre trato de confianza o de familiaridad y trato de respeto, advierte de que

los conceptos de confianza y respeto no son siempre adecuados si se aplican de manera estricta [...] se usan a veces las formas características del llamado trato de confianza (tú, vos) en situaciones en las que el que habla no conoce personalmente a su interlocutor, por lo que parece que no pueda tener confianza con él (2009 I: 1251).

Para Calderón Campos (2010: 232-233), las etiquetas como deferencia y respeto parecen poco acertadas, ya que estos conceptos "nos llevan a un terreno muy resbaladizo", son "válidos para el análisis pragmático de situaciones concretas, pero no para la descripción general del sistema hablado por casi cuatrocientos millones de personas". En China, investigadores como Lü (1982), Zhu (1982), Chen (1983), Xu (2003), Liu (2009), etc. también realizaron estudios poniendo de relieve la necesidad de matizar el modelo de análisis propuesto por Brown y Gilman, así como precisando los matices significativos asociados a las formas pronominales de tratamiento.

En definitiva, teniendo en cuenta locomplejos que son los aspectos socioculturales (el uso de $T / V$ en distintos ámbitos y el fenómeno simétrico y asimétrico) y pragmáticos (valores semánticos y pragmáticos que puedan adquirir), para cumplir el objetivo de este estudio, el primer paso consiste en profundizar en el conocimiento de los valores semántico-pragmáticos que conllevan $T$ y $V$ en español y chino.

\section{METODOLOGÍA DE LA INVESTIGACIÓN}

En los estudios empíricos dedicados a las FPT, son relativamente frecuentes tres métodos de investigación (Song y Wang, 2014: 119). El primero consiste en pasar cuestionarios y/o entrevistar a un determinado grupo de hablantes, lo que permite investigar el uso de las fórmulas de tratamiento actuales, desde una perspectiva diastrática y diafásica, en una comunidad concreta y en ciertos grupos de hablantes. Los estudios de Pedroviejo Esteruelas (2006), Kim (2006), Jang (2010), Bestard Revilla (2012), entre otros, responden a este planteamiento. En segundo lugar, autores como 
Martínez Gavilán (1988), Jaime de Arrieta y Cuadros de Béssega (1997), García Godoy (2010), etc. parten de textos históricos -sean literarios, gramaticales, cartas personales, etc.- analizando las fórmulas de tratamiento utilizadas en una época determinada, o, más globalmente, estudiando las FPT desde el punto de vista diacrónico. Por último, Rigatuso (2000), Aijón Oliva (2009), Song (2010), etc. se basan en distintos campos de los medios de comunicación (publicidad tanto impresa como digital, entrevistas de televisión y radio) con el objetivo de investigar las FPT en lenguajes especializados, como, por ejemplo, el uso de tú y usted como estrategias de estilo y persuasión en la comunicación publicitaria, o la sociopragmática de las FPT en anuncios radiofónicos y en discursos de publicidad.

En nuestro caso, después de analizar las propiedades de los variados tipos de materiales, decidimos usar series de televisión como base de datos por las siguientes razones. En comparación con las películas, las series de televisión tienen argumentos más largos y completos, con relaciones personales más complejas; poseen más conflictos dramáticos y más conversaciones entre los personajes. En relación con las novelas, las series expresan la dimensión espacio-tiempo de forma más completa; asimismo (especialmente si comparamos las novelas con las series basadas en ellas), presentan un mayor número de diálogos entre los personajes. En cuanto a las obras de teatro, estas tienen, a semejanza de las series, abundantes diálogos y complejas relaciones, pero son relativamente más cortas en su duración. De este modo, las series nos permiten extraer más segmentos conversacionales.

Somos conscientes de que las conversaciones grabadas tienen mayor grado de espontaneidad que las series. No obstante, sus limitaciones son indiscutibles a la hora de registrar todos los usos pronominales de tratamiento y de recoger testimonios fidedignos del habla real en todas o en numerosas situaciones. Por ejemplo, resultaría imposible acceder a la comisaría para grabar la conversación entre la policía y un criminal; asimismo, sería muy difícil registrar los diálogos íntimos entre parejas. Sin embargo, estos casos sí pueden abordarse a partir de las series. Por otro lado, en este tipo de programas los actores hacen hincapié en la interpretación del personaje y actúan dándole credibilidad. Así que, una vez comparados todos los posibles materiales, concluimos que las series son el medio ideal para llevar a cabo el estudio.

\subsection{Criterios para la selección de las teleseries}

En la selección de las series para formar el corpus hemos tenido en cuenta los siguientes criterios:

1. Como el objeto de esta sección consiste en comparar las FPT en español actual peninsular y en chino, las series deben haber sido producidas en los últimos años, y el relato debe estar basado en la vida cotidiana de la actualidad.

2. Es preferible que las series abarquen de la forma más amplia posible distintos entornos sociales, lo cual supone la ventaja más relevante sobre la grabación de conversaciones reales. 
3. Asimismo, preferimos elegir las series con suficientes personajes y complejas relaciones personales, lo que nos permitirá obtener una gran red social, así como observar las conversaciones de los mismos interlocutores en distintos contextos comunicativos, o bien diferentes hablantes en una misma situación.

4. La mayoría tanto de los actores como de los personajes de las series pertenecen a lo que nosotros consideramos primer tramo de edad (la juventud, es decir, menores de veinticuatro años) y a una parte del segundo tramo de edad (entre veinticinco y treinta años), lo cual ha de ponerse en relación con el hecho de que exportaremos el resultado a la enseñanza de las FPT a los alumnos chinos de esas edades.

5. También damos prioridad a las series que han ganado premios en el sector, teniendo en cuenta que dichos premios garantizan en cierto modo la calidad de la series, así como el nivel de la interpretación del actor, en otras palabras, la naturalidad y credibilidad en su actuación.

Por estos motivos, se han elegido dos teleseries españolas y una china. Las españolas son Desaparecida (2007) y Los protegidos (2010); la china se llama 我的青春谁 做主 (Mi juventud depende de mî). Nos basamos en estas dos series españolas porque la suma de sus datos (la duración total, la cantidad de las relaciones, la distribución de la edad, así como el porcentaje de los ámbitos) equivale al programa chino. De este modo, resumiendo las dos teleseries españolas y comparándolas con la china, llegamos a poder adquirir un corpus equilibrado, cuyos datos comparativos se muestran a continuación:

Tabla 1. Comparación de los datos técnicos del corpus

\begin{tabular}{|c|c|c|c|}
\hline \multicolumn{2}{|l|}{ DATOS } & ESP. & CHN. \\
\hline \multicolumn{2}{|l|}{ Duración total } & $1.885 \mathrm{~min}$. & $1.792 \mathrm{~min}$. \\
\hline \multicolumn{2}{|l|}{ Interlocutores } & 83 & 77 \\
\hline \multicolumn{2}{|l|}{ Sexo (varón/mujer) } & $55 \% / 45 \%$ & $53 \% / 47 \%$ \\
\hline \multirow{3}{*}{ Edad $^{4}$} & 1. ${ }^{\mathrm{a}}$ edad & $36 \%$ & $35 \%$ \\
\hline & 2. ${ }^{\mathrm{a}}$ edad & $46 \%$ & $51 \%$ \\
\hline & 3. ${ }^{\mathrm{a}}$ edad & $18 \%$ & $14 \%$ \\
\hline \multirow{5}{*}{ Porcentaje de los cinco ámbitos ${ }^{5}$} & Familiar & $43 \%$ & $47 \%$ \\
\hline & Social & $8 \%$ & $10 \%$ \\
\hline & Laboral & $14 \%$ & $11 \%$ \\
\hline & De solidaridad & $19 \%$ & $17 \%$ \\
\hline & Escolar & $16 \%$ & $15 \%$ \\
\hline
\end{tabular}

\footnotetext{
${ }^{5}$ En nuestro trabajo, dividimos los tramos de edad en grupos de 24 años cada uno: primer tramo (menores de veinticuatro años), segundo tramo (entre veinticinco y cuarenta y nueve años), tercer tramo (entre cincuenta y setenta y cinco años), cuarto tramo (de setenta y cinco en adelante).

${ }^{6}$ Es bastante común en este tipo de estudios que se agrupen las diversas relaciones en ciertos ámbitos: familiar, social, laboral, escolar, de solidaridad. El ámbito familiar consiste en formas de trato a los padres, tíos, cuñados, hermanos y otros parientes; el ámbito laboral tiene lugar en los sitios de trabajo con informantes como jefes, colegas y subalternos; el ámbito social parte de amistades, conocidos y desco-
} 
Como se ve en la tabla 1, los textos conversacionales de ambos idiomas son similares, tanto en la duración y en el número de personajes válidos para el estudio como en la proporción de los cincos ámbitos en que se desarrollan las conversaciones extraídas.

\title{
3.2 Procesamiento del corpus
}

En el corpus del presente estudio, se identificaron las FPT en distintas tipologías de relación interpersonal, ya sea, por ejemplo, la interacción propia de un padre con su hija adoptada, o bien, la del criminal con la familia del asesinado; y, a partir de estos resultados, se agruparon en los cinco ámbitos señalados, con el fin de observar el tratamiento más utilizado en cada uno. Asimismo, se registró la alternativa entre $T / V$ y se observó su causa desde el punto de vista pragmático. De este modo, se diseñaron dos documentos, uno en formato de Microsoft Excel, y otro por medio de Microsoft Word para cada teleserie. En el primero, se han establecido ficheros en los que se proporcionan datos pertinentes sobre los interlocutores de la serie (nombre, edad, sexo y profesión), y registros de las formas simétricas y asimétricas de tratamiento. En el segundo, se han transcrito las conversaciones enteras que nos sirven para el análisis. Todo el proceso se ha llevado a cabo de manera totalmente manual, escuchando y repitiendo cada frase cuantas veces ha sido necesario hasta poder registrar todas las FPT, y realizar una transcripción escrita precisa.

En la transcripción de las conversaciones, se han utilizado los símbolos de Val.Es.Co. (Briz Gómez: 1995), a los cuales añadimos algunos propios que resultan necesarios para el idioma chino. Estos símbolos son:

\author{
: Cambio de hablante \\ A: Intervención de un hablante identificado como A \\ $\S$ Sucesión inmediata, sin pausa apreciable, entre dos \\ emisiones de distintos hablantes \\ [ Lugar donde se inicia un solapamiento o superposición \\ ] Final del habla simultánea \\ / Pausa corta, inferior al medio segundo \\ // Pausa entre medio segundo y un segundo \\ /// Pausa de un segundo o más \\ (4») Silencio (lapso o intervalo) de 4 segundos; se indica el \\ número de segundos en las pausas de más de un segundo, \\ cuando sea especialmente significativo \\ $\uparrow \quad$ Entonación ascendente \\ $\downarrow \quad$ Entonación descendente \\ $\rightarrow \quad$ Entonación mantenida o suspendida \\ PESADO Pronunciación marcada o enfática
}

nocidos en distintos espacios sociales; el ámbito de solidaridad hace referencia a amistades, conocidos y desconocidos en situaciones comunicativas propiciadas por eventos de tipo festivo; el ámbito escolar se refiere a la relación entre profesores y alumnos en instituciones educativas. 


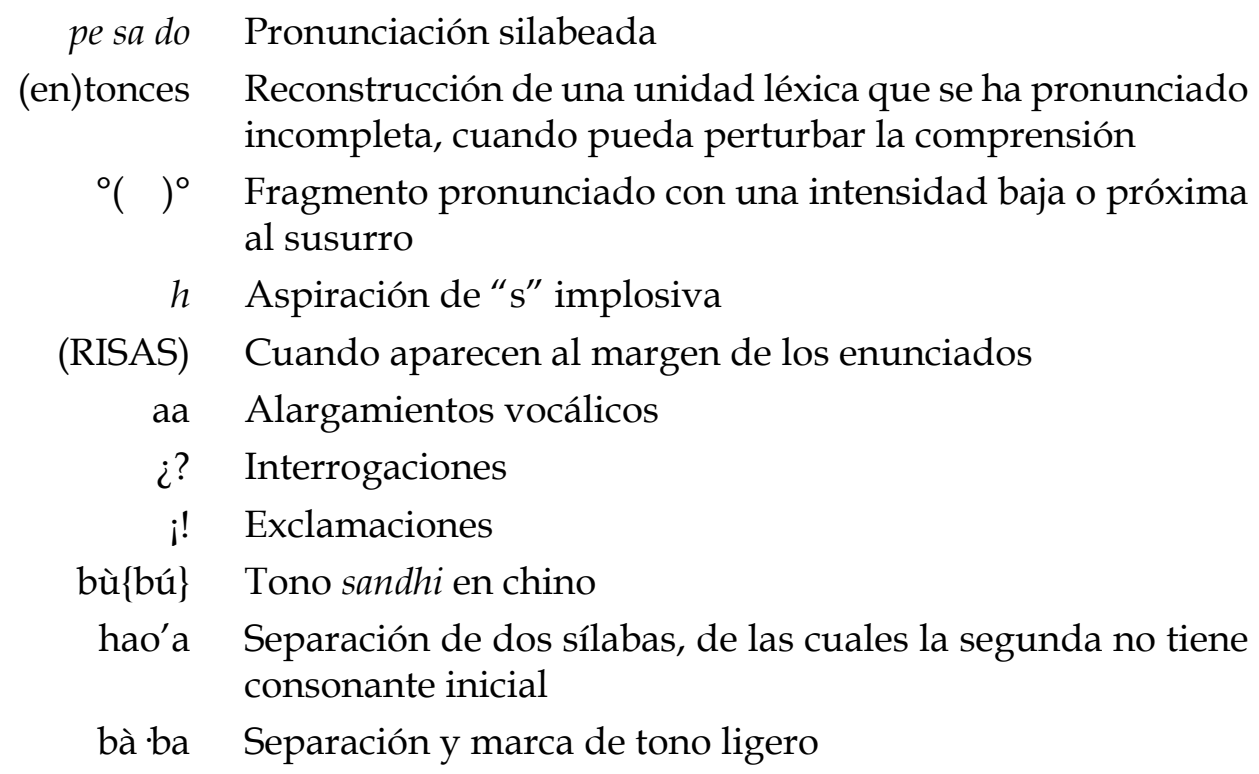

\subsection{Aspectos pragmáticos}

Una vez analizado el corpus, hemos observado que las FPT en ambos idiomas presentan tanto similitudes como diferencias en cuanto a sus valores semánticopragmáticos. Antes de entrar en detalles, parece conveniente referirnos a una clasificación de las FTP que resulta válida para ambos idiomas y que guarda una estrecha vinculación con esos valores.

Según la alternativa de $T / V$ en los actos comunicativos, consideramos que las FPT pueden situarse en estado estático y en estado dinámico. Las FPT en estado estático son formas de tratamiento permanente, que suelen ser usadas por una persona como medio para dirigirse a otra en cualquier situación, como por ejemplo, en el ámbito familiar, en la conversación entre padres e hijos siempre se usa el trato de tú. Las formas en el estado dinámico, por su parte, son formas de variación instantánea, que se refieren al fenómeno lingüístico en el que el emisor usa distintas formas de tratamiento con un mismo interlocutor en un mismo acto comunicativo con una intención comunicativa determinada. En otras palabras, el hablante modifica la forma de tratamiento con el objetivo de expresar algún sentido semántico especial o distinto.

Si bien muchos autores han ejemplificado etiquetas semánticas de $T / V$, estas etiquetas no se localizan en un mismo nivel. Por un lado, consideramos que tanto $T$ como $V$ solo poseen valores semánticos naturales cuando se encuentran en estados estáticos. Los valores son, por ejemplo, familiaridad, solidaridad en el caso de $T$, y respeto, cortesía, formalidad en el caso de $V$. Por otro lado, en lo referente a las etiquetas como enojo, molestia, desprecio, humillación, impaciencia, etc. (Rodríguez Mendoza, 2003: 73; Calderón Campos, 2010: 232-233; Placencia, 2010: 367, etc.), creemos que corresponden a un estado dinámico. Los pronombres de tratamiento las podrán adquirir solo y exclusivamente cuando se realiza la variación instantánea. En otras palabras, esas etiquetas no son sino "productos" generados por el hecho de que se da $T$ en contextos de tratamiento permanente de $V$, así como en aquellos en que se usa $V$ en una relación 
estable de T. Desde esta perspectiva, los valores del estado dinámico no son significados propios o consustanciales de los pronombres.

A continuación, se ponen como ejemplos algunas secuencias, con el propósito de que se tenga una idea sobre la generación de valores semántico-pragmáticos a través de la variación instantánea, es decir, $T-V-T$ y $V-T-V$.

Fragmento conversacional 1

- Fuente: Desaparecida

- Duración: 4 segundos

- Participantes: Blanca, 18 años, hija de Sierra; Sierra, sobre 45 años, teniente de la Guardia Civil

- Ámbito: Familiar

- Relación: Padre e hija

- Antecedente: Sierra es teniente de la Guardia Civil. Está divorciado y su hija Blanca vive con su exmujer. Como a la chica le resulta insoportable la convivencia con su madre, abandona la casa sin avisar a nadie y va a buscar a su padre. Al enterarse de que su hija ha desaparecido, está nervioso porque en ese momento precisamente está investigando la desaparición de una chica de la edad similar. Cuando Blanca encuentra a su padre, este la lleva a todas partes para no perderla de vista. De este modo, cuando está de servicio y entra en un bar, también lleva a su hija.

Situación comunicativa: En un bar, Sierra pide a su hija que no se mueva de ahí.

- Texto transcrito:

1 Sierra:

quédate aquí

2 Blanca:

a sus órdenes/ mi tenieente

En toda la serie Desaparecida, esta supone la única ocasión en que Blanca trata a su padre de usted. Según nuestro modo de ver, lo que ella pretende comunicar es una especie de queja por la orden que recibe previamente de su padre, por el trato autoritario que supone; implícitamente, es como si le estuviese diciendo "me tratas como si fuese uno de tus subordinados". Así pues, consideramos que el trato de usted en este caso tiene un valor irónico. Asimismo, se ha encontrado otro ejemplo de ironía y/o enojo en Los protegidos.

Fragmentación conversacional 2

- Fuente: Los protegidos

- Duración: 20 segundos

- Participantes: Leo, Sandra, Ana, María, Juan, compañeros del segundo año de bachillerato

- Ámbito: De solidaridad

- Relación: Compañeros del instituto

- Antecedente: Los compañeros de clase están haciendo una fiesta en la casa de campo de Leo. La música está a todo volumen. Últimamente, Leo siente algo por Sandra pero esta chica parece no corresponderle. Esta noche, Leo está nervioso y preocupado porque Sandra ha quedado con él. 
Situación comunicativa: Leo está sentado en el patio con los otros tres chicos. Sandra le dirige a él.

- Texto transcrito:

1 Sandra: chicos esto está dando mucho

2 Juan: niña pareces nueva/

3 ¿por qué te crees que he venido? $\downarrow$

4 Ana: $\quad$ oYE yo creo que estos dos se están dando el lote eeh $\uparrow$

5 Juan: $\quad$ (MIRA A LEO) tío tráete algo para echarme a la garganta/

6 que estoy sediento

7 Leo: ¿por qué no vas tú guapo?^

8 Juan:

El personaje de Juan se había tomado la confianza de pedirle a Leo que le trajese una bebida y este reacciona con enojo: “por qué no vas tú guapo?”, porque lo considera "demasiado pedir", es decir, un abuso de confianza (además, véase que Juan hace esa petición con un imperativo, de forma poco cortés); así, el trato de usted con el que reacciona luego el personaje de Juan, pidiendo disculpas además, supone una forma irónica de invertir totalmente ese abuso de confianza previo, pasando a tratarle como si fuese un extraño, es decir, con un alto grado de cortesía que está fuera de lugar y que contrasta enormemente con la forma poco cortés (o de gran/excesiva confianza) que se utilizó antes; esa reacción irónica transmite un mensaje implícito de "tampoco te lo tomes así", para reprochar el enojo mostrado por el personaje de Leo.

En el caso del chino, los tratamientos 你 $(T$, sigular)/你们 $(T$, plural) y 您 $(V$, singular)/您们 ( $V$, plural), cuando se sitúan en el estado estático, poseen los mismos valores que $T / V$ en español; cuando están en el estado dinámico, el $V$ presenta mayor diferencia, que consiste en los valores cariño y acercamiento, ya que en el español ${ }^{7}$ esta variante se usa para distanciarse. A continuación, se especifican estos valores con ejemplos.

Fragmento conversacional 3

- Fuente: Mi juventud depende de mí

- Duración: 15 segundos

- Participantes: Qian Xiaoyang, sobre 25 años, novia de Fang Yu; Fang Yu, sobre 25 años, mecánico de un taller; la abuela de Fang Yu, sobre 75 años

- Ámbito: Familiar

- Relación: Novia de nieto-abuela

- Antecedente: Qian Xiaoyang está enfadada con Fang Yu. Va a la casa de su abuela y le explica a la anciana todo lo ocurrido entre ellos. Cuando llega Fang Yu, su abuela se enfada y quiere reñir al nieto.

\footnotetext{
${ }^{7}$ El español, en este caso, se refiere al peninsular, puesto que nuestro corpus está compuesto por teleseries producidas en España. Sin embargo, cabe mencionar que de hecho se ha observado que en Colombia los hombres dirigen usted a hombres con la intención de expresar intimidad y a mujeres para crear un efecto de confianza (Placencia, 2010: 352).
} 
- Situación comunicativa: En la casa de la abuela de Fang Yu.

- Texto transcrito:

1 Qian: năi $\cdot$ nai năi $\cdot$ nai nǐ bié shēngqì

奶奶奶奶你 $(\mathrm{T})$ 别生气。

2 nǐ Ž̌en • me huíshìr • a $\downarrow /$ Yİ huí • lai jiù rě

năi $•$ nai shēngqì

你怎么回事啊, 刚一回来就惹奶奶生气。

3

Àaiya năi • nai/ nín bié shēngqì

哎呀奶奶您 $(V)$ 别生气啊

4

ZǑU/ zán • men chū $\bullet$ qu bāiche ${ }^{\circ}(q u)^{\circ}$

走, 咱俩出去羒扯去。

- Traducción:

1' Qian: (A la abuela) No te enfades abuela.

2' (A Fang Yu) ¿Qué haces! ¿Por qué quemas a la abuela nada más que llegar a casa!

3' (A la abuela) Ay no se enfade abuela, amor de mi vida

4' (A Fang Yu) Vamos a hablar fuera.

En la serie Qian trata permanentemente de tú a la abuela de Fang Yu, pero al notar que está enfadada con su nieto, en la línea 3, para aliviarla, cambia a usted con el fin de expresar cariño.

Fragmento conversacional 4

- Fuente: Mi juventud depende de mí

- Duración: 15 segundos

- Participantes: Qian Xiaoyang, sobre 25 años, prima de Zhao Qingchu;

Zhao Qingchu, sobre 27 años, prima de Qian Xiaoyang

- Ámbito: Familiar

- Relación: Entre primas

- Antecedente: Zhao Qingchu está saliendo con Zhou Jin, que es director comercial de una gran empresa. La prima de Zhao Qingchu, Qian

Xiaoyang, se aprovecha de esta situación y consigue un puesto de trabajo en la empresa por tener ese contacto. Cuando se entera de lo que ha hecho su prima, Zhao Qingchu se enfada.

- Situación comunicativa: En casa, Zhao Qingchu acaba de llegar

- Texto transcrito:

1 Zhao: QIÁN XIǍ0 YÀNG!

钱小样!

2 Qian: dào! Nín huí • lai • le/ nín xīnkǔ • le

到! 您 $(\mathrm{V})$ 回来了, 您 $(\mathrm{V})$ 辛苦了。

3 Zhao: nǐ zuò zéi xīn xū $\cdot 1 \mathrm{e} \cdot$ ba

你做贼心虚了吧。

4 Qian: heihei $\downarrow /{ }^{\circ}$ (nǐ dōu zhīdào $\left.・ 1 e\right)^{\text {o }}$

嘿嘿, 你 $(\mathrm{T})$ 都知道了...... 
- Traducción:

1' Zhao: ¡Qian Xiaoyang!

2' Qian: ¡Sí! Ya está en casa, ¿cómo se encuentra usted?

3' Zhao: No me hagas la pelota.

4' Qian: Bueno, ¿ya te enteraste de que...?

Como Qian sabe que ha hecho algo que habrá molestado a su prima Zhao, cuando esta llega a casa, la trata de usted para mostrar un sentimiento de acercamiento, con el propósito de suavizar la situación. Eso también puede ser justificado a través de la respuesta de Zhao de la línea 3.

De este modo, se elabora un esquema de los valores pragmáticos de los tratamientos en español y chino (tabla 2).

Tabla 2. Valores pragmáticos de los tratamientos en ambos idiomas

\begin{tabular}{|c|c|c|c|c|}
\hline \multirow[b]{4}{*}{$\begin{array}{c}\text { Estado } \\
\text { dinámico }\end{array}$} & \multicolumn{4}{|c|}{ Valores de las formas de variación instantánea } \\
\hline & \multicolumn{2}{|c|}{ V-T-V (valores de T) } & \multicolumn{2}{|c|}{ T-V-T (valores de V) } \\
\hline & En español & En chino & En español & En chino \\
\hline & $\begin{array}{l}\text { intrusión, enojo, } \\
\text { condescendencia, } \\
\text { humillación, etc. }\end{array}$ & $\begin{array}{l}\text { intrusión, enojo, } \\
\text { condescendencia, } \\
\text { humillación, etc. }\end{array}$ & $\begin{array}{l}\text { distanciamiento, } \\
\text { frialdad, enojo, } \\
\text { impaciencia, } \\
\text { paternalismo, } \\
\text { etc. }\end{array}$ & $\begin{array}{c}\text { distanciamiento, } \\
\text { frialdad, enojo, } \\
\text { impaciencia, } \\
\text { paternalismo, } \\
\text { cariño, } \\
\text { acercamiento, etc. }\end{array}$ \\
\hline \multirow{4}{*}{$\begin{array}{l}\text { Estado } \\
\text { estático }\end{array}$} & \multicolumn{4}{|c|}{ Valores de las formas permanentes } \\
\hline & \multicolumn{2}{|c|}{$\mathbf{T}$} & \multicolumn{2}{|c|}{$\mathbf{V}$} \\
\hline & En español & En chino & En español & En chino \\
\hline & $\begin{array}{c}\text { familiaridad, } \\
\text { solidaridad, } \\
\text { confianza }\end{array}$ & $\begin{array}{l}\text { familiaridad, } \\
\text { solidaridad, } \\
\text { confianza }\end{array}$ & $\begin{array}{l}\text { respeto, cortesía, } \\
\text { formalidad }\end{array}$ & $\begin{array}{l}\text { respeto, cortesía, } \\
\text { formalidad }\end{array}$ \\
\hline
\end{tabular}

\subsection{Aspectos socioculturales}

En términos generales, en español, el porcentaje de aparición de la variante $T$ supone más del doble que el de la forma $V$ (68\% vs. $32 \%$, respectivamente); en chino, en cambio, el $V$ presenta un índice de frecuencia bastante alto: un $56 \%$ de $T$ frente a un $44 \%$ de $V$. A continuación, se analiza por ámbitos el uso de estas variantes.

En el ámbito familiar, en el caso del español, el tratamiento $T$ casi es la forma unánime. En todas las relaciones familiares registradas, el uso de $T$ ocupa aproximadamente un $100 \%$ de las relaciones. Estas relaciones se producen entre padres e hijos, entre primos, entre hermanos, entre cuñados, entre tíos y sobrinos, y entre padres e hijos adoptados. De este modo, todas estas relaciones constituyen un ámbito democrático e igualitario. Solamente se encuentra un enunciado dirigido de hija a padre en el que se utiliza la forma $V$, que se trata de variación instantánea (véase 
el fragmento conversacional 1). A diferencia del español, el $V$ en chino, en el ámbito familiar, tiene un porcentaje global relativamente alto, con un $47 \%$ de aparición. Se observa que, en el tratamiento entre los familiares de la misma generación así como en el de los parientes de nivel alto a los de menos estatus, el $T$ es la única forma. Sin embargo, los emisores de menos estatus alternan $T / V$ cuando tratan a los mayores. En todas las relaciones de este tipo -de hijos a padres, de nietos a abuelos, de sobrinos a tíos- se dan múltiples casos de la alternativa $T / V$. Además, se nota que, en el idioma chino, los yernos/nueras usan única y asiduamente la forma de respeto $V$ con sus suegros, aunque a sus padres los tratan de $T / V$ alternativamente. Asimismo, los novios e incluso amigos de los hablantes dirigen respetuosamente $V$ a sus padres. Esto supone un rasgo diferencial respecto al español.

En el ámbito social, tanto en español como en chino, el $V$ tiene una frecuencia más elevada que $T$, con el porcentaje del $68 \%$ frente al 32\% y el 79\% frente al 21\%, respectivamente. El ámbito social, como se explicaba anteriormente, se refiere a las conversaciones realizadas entre conocidos y/o desconocidos en lugares públicos, tales como el Ayuntamiento, la Comisaría o la Oficina de la Guardia Civil, así como en el colegio, en la iglesia, en el cementerio, en el escenario de un crimen, en un hospital, o en un taller. En todas las relaciones pertenecientes a este ámbito, $V$ es la forma dominante entre ciudadanos y los guardias civiles. Tomamos la teleserie Desaparecida como ejemplo: a lo largo de sus trece episodios los guardias civiles, fuese cual fuese su rango, reciben un $100 \%$ de $V$ en las conversaciones. De acuerdo con el corpus, las variables socioculturales que intervienen en la elección de $T / V$ consisten principalmente en la relación entre los interlocutores, así como la edad del receptor. En otras palabras, menos relación entre los dos y más edad del oyente favorecen la aparición de $V$, conclusión que coincide con los estudios de Medina López (1991), Morín Rodríguez (2001, 2002) y Rodríguez Mendoza (2003).

En el ámbito laboral, como era de esperar, debido al carácter formal de este tipo de interacciones comunicativas, también se observa una alta proporción de $V$ $(46 \%)$. En este contexto, las relaciones analizadas son: sargento, teniente y capitán en la Guardia Civil; oficial, agente y comisario en la Comisaría; profesores, jefe de estudios y director en el colegio; camarero y dueño de un bar; mecánico y propietario de un taller; enfermeras y médicos. La alta frecuencia más representativa de $V$ ha aparecido en las relaciones de la Guardia Civil (63\%), ya que obviamente consiste en un entorno formal y con la jerarquía relativamente bien establecida. En chino, el $V$ presenta el índice de un $52 \%$ respecto a $T$. Sin embargo, se observa una asimetría notable en estas relaciones. Los subordinados tratan principalmente de $V(87 \%)$ a los superiores, mientras que estos mismos se dan T (91\%).

En el ámbito escolar, se observa que en español la forma $T$ es la más usada, con un $79 \%$ frente a un $21 \%$ de $V$, y el tratamiento simétrico es predominante. En Los protegidos, se registra un caso en el instituto en el que el profesor trata de usted a los alumnos, mientras que estos le tutean: 
Fragmento conversacional 5

- Fuente: Los protegidos

- Duración: 75 segundos

- Participantes: Director, en torno a los 40 años, da clase de literatura; Lucas, 14 años, alumno; Pablo, 14 años, alumno; Hugo, 14 años, alumno

- Ámbito: Escolar

- Relación: Profesor-alumno

- Antecedente: Lucas, Pablo y Hugo estudian en el mismo grupo. Para Pablo, Lucas es un chico raro, que, aparte de Hugo, no tiene otro amigo. El director del colegio les da clase de literatura, $y$, una vez, les pide llevar una foto familiar para hacer un trabajo en clase.

- Situación comunicativa: En clase, el director pasa por el pupitre de Lucas.

- Texto transcrito:

1 Director: Castillo/ no veo sus fotos

creo que lo dije bien claro/

3

sin fotos no se puede hacer trabajo

4 Lucas: mira/ es que no tengo ninguna

5 Director: ¿cómo que no va a tener fotos de sus padres? $\downarrow$

6 Lucas: vivo con mis tíos

7 Director: eso no me vale como excusa/

8

Lucas: siempre hay un álbum de fotos por allí

Director:

Hugo: $\quad$ iy eso?^ (VUELVE LA CABEZA PARA HABLAR CON LUCAS)

Director: Hugo// (VUELVE A MIRAR A HUGO) a lo suyo

Lucas: $\quad{ }^{\circ}(\mathrm{no} / \mathrm{no})^{\circ}$ les gusta mi forma de ser

Director: $\quad$ isu forma de ser? $\downarrow / / /$

bueno pero eso no tiene nada que ver con la biología§

Pablo:

¿cómo que no tiene nada que ver? $\uparrow$

vamos a ver (RISA)/ pero si ya te lo dije yo/

que este es mariquita de fijo [(RISA)]

Director: [SILENCIO]/

no quiero ni un SOLO comentario más (4») a recoger

Hugo: (HUGO HABLA CON PABLO) eso// tú a callar

Pablo: $\quad$ (PABLO MIRA A LUCAS) sí sí/ entoncees $\downarrow /$

¿cómo es eso de/ tu forma de ser?^//

ves $\uparrow /$ (RISA) que ya te lo dije YOo

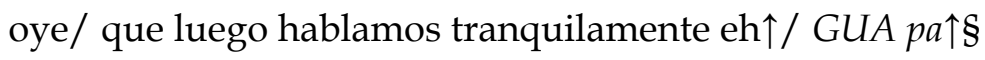

$$
\S \text { Pablo } \downarrow /
$$

no quiSIEra hablar más tarde con usted 
En la universidad el tratamiento simétrico también es predominante, sea tuteante o de usted. Los factores que intervienen en la elección de la forma son la edad del profesor, la relación que tienen, y el estatus del profesor. En el caso del chino, el $T$ supone la forma unánime de tratamiento de profesores a alumnos. En cambio, los estudiantes prefieren tratar a sus profesores de $V$, y cuanto más alto sea el nivel educativo, más probable es la aparición de la forma $V$. Más concretamente, el uso de $V$ en la Escuela Primaria presenta un bajo índice de porcentaje, un $26 \%$; en el bachillerato, un 54\%; y en la educación universitaria, un 78\%. Este fenómeno llama mucho la atención en contraste con lo ocurrido en la sociedad española.

El último de los ámbitos estudiados en esta investigación es el de solidaridad. En español, como cabría esperar, los porcentajes de aparición de la variante $T$ son casi tres veces más altos que los de $V$, con un $73 \%$. Igual que en el social, se registran conversaciones entre amigos, conocidos y/o desconocidos realizadas en una fiesta de pueblo, en una fiesta de cumpleaños, en una cena en casa con invitados, así como en una actividad escolar de padres, en el bar, en calles, en una feria, en un huerto, en un parque. Según el corpus, los principales factores que implican el uso de $V$ son la variable "poca/ninguna relación" entre los interlocutores, y la variable "mayor edad del receptor". En este ámbito del corpus chino, $T$ también es la forma mayoritaria, con un $65 \%$ de frecuencia de aparición. Se registran conversaciones entre amigos, conocidos y/o desconocidos realizadas en fiestas de cumpleaños, en fiestas de boda, en una comida familiar con invitados, así como en una actividad escolar de padres, en el bar, en las calles, en una feria, en un parque. El uso de la variante $V$ se produce fundamentalmente en los tratamientos entre interlocutores con poca relación y mucha distancia de edad.

Sobre los tratamientos simétricos y asimétricos, en todas las conversaciones extraídas del corpus español, se ha observado un $91 \%$ de tratamientos simétricos frente a un $9 \%$ de asimétricos, los cuales han aparecido principalmente en el ámbito social, en concreto, entre los guardias civiles y ciudadanos. Los guardias civiles -el Teniente Sierra y la Sargento Laura- tratan a seis personas de $T$ y reciben de ellos el $V$, por ejemplo, cuando se dirigen a unos jóvenes del primer tramo de edad o a unas prostitutas, debido al alto estatus y más edad, les dan $T$ mientras que reciben $V$. Cabe decirse que la asimetría, en muchos casos, no aparece al principio de un acto comunicativo, sino que, a lo largo del desarrollo del argumento, al darse cuentan de que algunos son sospechosos, los dos guardias civiles cambian la forma de $V$ a $T$, hecho que tiene que ver con los valores pragmáticos de $T$ cuando sufre la variación instantánea.

En cuanto al corpus chino, hemos de confirmar que la forma asimétrica de tratamiento resulta absolutamente llamativa ( $37 \%$ en chino vs. $9 \%$ en español). Se ha observado que en cualquier ámbito, cuando se trata de relaciones unidireccionales, como por ejemplo, hijos y padres, nietos y abuelos, yernos y suegros, empleados y jefes, alumnos y profesores, entre otros, es posible encontrar casos de asimetría. Es decir, los interlocutores de nivel bajo (menos edad o menos estatus) emplean mayoritariamente $V$ 
y reciben $T$. Su origen, en nuestra opinión, se encuentra en las características históricas y sociales de cada país.

En España, o, en términos más generales, en el mundo occidental, el tratamiento recíproco ha venido ganando terreno al no recíproco o asimétrico a partir de la primera mitad del siglo XX, momento en el que los movimientos políticos igualitarios característicos influyeron especialmente en la extensión progresiva de las formas de confianza e igualdad. En la segunda mitad de ese siglo tuvo mayor influencia en el creciente desarrollo de las formas de confianza el valor que se otorga en el mundo moderno a la juventud y al hecho mismo de ser joven, en contraste con la consideración que en otros tiempos tuvo el peso de la experiencia o de la madurez (Real Academia Española, 2009, I: 1252). En definitiva, en los últimos cien años en español las formas de tratamiento han pasado de jerárquicas a democráticas e igualitarias.

Sin embargo, en el caso del remoto país asiático, donde aún predomina el tratamiento asimétrico, a lo largo del último siglo su sociedad todavía no se ha convertido en una sociedad igualitaria. Pues se observa que los interlocutores de mayor edad son los que principalmente reciben el $V$. La razón de ello se debe a que, en la cultura china, la vejez no significa ni debilidad ni incapacidad. China es un país con una historia de miles de años. El homo sapiens hace su aparición en el territorio que actualmente ocupa la República Popular China unos 40 mil años atrás. Hace alrededor de unos 10 mil años se empieza a cultivar arroz en el río Yangtsé. En el VIII milenio a. C. las culturas de la zona del valle del río Amarillo se hicieron sedentarias; un milenio después comenzaría la domesticación de animales; entre el VII y VI milenio a. C. surgen las primeras culturas neolíticas. Sin embargo, sus registros escritos aparecieron mucho más tarde: se remontan al siglo XVI a. C. De este modo, a lo largo de tantos siglos sin escritura, los habitantes se transmitían las informaciones técnicas o agrícolas de generación en generación de forma oral. Así pues, progresivamente, los mayores se convertían en "tesoros vivos" puesto que son ellos los que han vivido más tiempo y saben más y, en consecuencia, eran tratados como sabios. Desde esta perspectiva, el respeto hacia las personas de mayor edad es una costumbre legendaria y en la actualidad sigue siendo lo mismo.

\section{DIDÁCTICA DE LAS FPT EN EL AULA DE E/LE EN CHINA}

En la Dedicatoria al Conde de Lemos, segunda parte de El Quijote, Cervantes escribió:

[...] el grande Emperador de la China, pues en lengua chinesca habrá un mes que me escribió una carta con un propio, pidiéndome, o, por mejor decir, suplicándome se le enviase, porque quería fundar un colegio donde se leyese la lengua castellana, y quería que el libro que se leyese fuese el de la historia de Don Quijote. Justamente con esto me decía que fuese yo a ser el rector de tal colegio.

El sueño de Cervantes no pudo hacerse realidad hasta mediados del siglo XX. Desde la fundación del primer centro universitario de enseñanza de español en 1952, 
hasta la fecha, la E/LE en China ha experimentado gran desarrollo y ha conseguido notables éxitos, en concreto, la carrera del Grado en Filología Hispánica se ofrece en sesenta y cuatro universidades.

\subsection{Descripción del manual Español moderno}

El motivo de elegir el Español moderno (Dong \& Liu, 1999) como corpus para analizar se debe a que, por un lado, es un trabajo realizado en China por hispanistas chinos y se focaliza absolutamente en los alumnos chinos, en lo referente a su aprendizaje del español; por otro lado, supone el manual más complejo, más estructurado y más sistemático de los que existen en este país. Desde hace quince años casi todos los alumnos que se graduaron en Filología Hispánica han utilizado este manual y hoy en día se usa en las sesenta y cuatro universidades en que se imparte la asignatura principal de la carrera. Tiene, por lo tanto, un papel fundamental en la enseñanza del español en China.

Este Español moderno consta de seis volúmenes. La primera edición de los dos primeros volúmenes se publicó en 1999; el tercero, el cuarto, el quinto y el último vieron la luz en 2000, 2001, 2003 y 2007 respectivamente. En la actualidad, en las universidades se emplean los primeros cuatro volúmenes en el primer y segundo año académico como manual principal, mientras que usar o no los últimos dos depende del programa de cada centro.

Las lecciones de los primeros cuatro libros tienen una estructura parecida. Cada lección empieza por un esquema de los contenidos clave, que consiste en un sumario de los temas de fonética y gramática para las primeras nueve lecciones del libro I, y en un resumen del contenido gramatical para el resto. En los esquemas no se ha encontrado ninguna referencia a las funciones comunicativas, ni a los conocimientos pragmáticos o socioculturales; todo el contenido se organiza a partir de la gramática. Cada lección se puede dividir en cinco apartados, que son el texto, el vocabulario, la fonética (lección 1-9 del volumen I) o el léxico (a partir de la lección 13), la gramática y los ejercicios sucesivamente. Normalmente, en el aula de E/LE, el profesor introduce ante todo el vocabulario enseñando las nuevas palabras, después explica los textos, trata la fonética y el léxico y, finalmente, se realizan los ejercicios.

\subsection{Análisis de la didáctica de las FPT en Español moderno}

Al revisar el manual en su conjunto, una sensación general que nos ha provocado es la ausencia de cualquier referencia a las funciones comunicativas, sección generalmente introducida en los manuales occidentales de didáctica de lenguas extranjeras. Conocimientos tan importantes como los provenientes de la pragmática o la sociolingüística tampoco se han introducido en los libros. Los seis volúmenes cubren las necesidades de un conocimiento de fonética, de gramática y de léxico, ya que el contenido de los textos está claramente al servicio de las estructuras gramaticales, pero no satisfacen las necesidades comunicativas a las que sirve el sistema gramatical, 
es decir, son justamente estas necesidades las que activan la competencia gramatical como recurso para una comunicación eficiente.

En el caso de las FPT, en estos volúmenes solo se le ha dedicado un espacio muy limitado: un punto del apartado de gramática en la lección 2, cuando se introduce el sistema pronominal (véase la figura 1), planteamiento que, en nuestra opinión, no las ha estimado adecuadamente, ya que no se menciona siquiera noción alguna sobre cuestiones tan importantes como los distintos sistemas pronominales en el mundo hispánico, los factores extralingüísticos que intervienen en su elección en un acto comunicativo, las variantes de la segunda persona singular (vos) y su paradigma verbal, el fenómeno simétrico y asimétrico del tratamiento, etc.

\section{语 法 GRAMÁTICA}

一、主格人称代词 (Pronombres personales, caso nominativo)：

计看下列图表:

\begin{tabular}{|c|c|c|c|c|c|c|c|c|}
\hline & & * & 数 & & & ) & 数 & \\
\hline & 阳 & 性 & 阳 & 性 & & 日性 & & 性 \\
\hline 第一人妳 & yo & 我 & yo & 我 & nosotros & 载们 & nosotras & 我们 \\
\hline 第二人秝 & tú & 你 & tú & 你 & vosotros & 你们 & vosotras & 你约 \\
\hline 第三人称 & $\begin{array}{l}\text { él } \\
\text { usted }\end{array}$ & & $\begin{array}{l}\text { ella } \\
\text { usted }\end{array}$ & 您 & $\begin{array}{l}\text { ellos } \\
\text { ustedes }\end{array}$ & $\begin{array}{l}\text { 他们 } \\
\text { 你们, }\end{array}$ & $\mid \begin{array}{l}\text { ellas } \\
\text { ustredes }\end{array}$ & $\begin{array}{l}\text { 们 } \\
\text { 你们，橴位 }\end{array}$ \\
\hline
\end{tabular}

1. usted 和 ustedes 是第二人称的礼统式。书写时可以分别缩

写为 Ud. 和 Uds.。在拉丁美洲地区, ustedes已经完全取代了 vosotros (tras)。

2. tú 和 él 带重音符号。

Figura 1. Sistema pronominal en Español moderno (págs. 28-29)

Su traducción:

Pronombres personales, caso nominativo:

\begin{tabular}{|r|c|c|c|c|}
\hline \multirow{2}{*}{$\begin{array}{r}\text { Género y } \\
\text { número }\end{array}$} & \multicolumn{2}{|c|}{ Singular } & \multicolumn{2}{c|}{ Plural } \\
\cline { 2 - 5 } Persona & masculino & femenino & masculino & femenino \\
\hline Primera persona & yo & yo & nosotros & nosotras \\
\hline Segunda persona & tú & tú & vosotros & vosotras \\
\hline Tercera persona & $\begin{array}{c}\text { él } \\
\text { usted }\end{array}$ & $\begin{array}{c}\text { ella } \\
\text { usted }\end{array}$ & $\begin{array}{c}\text { ellos } \\
\text { ustedes }\end{array}$ & $\begin{array}{c}\text { ellas } \\
\text { ustedes }\end{array}$ \\
\hline
\end{tabular}

1. usted y ustedes son las formas de respeto de segunda persona. En la escritura se pueden usar las abreviaturas Ud. y Uds. En América Latina, ustedes ha sustituido totalmente a vosotros (-as).

2. tú y él llevan tilde.

Además, entre lo que se ha explicado, también se observan problemas. En primer lugar, en la tabla se clasifica usted y ustedes como pronombres de la tercera persona, pero son formas de segunda persona según la nota 1, lo cual supone una explicación confusa que impediría la comprensión y utilización correctas por parte de los alumnos. Será necesario advertir a los alumnos que aunque el pronombre usted 
se refiere siempre al interlocutor -segunda persona-, a efectos gramaticales funciona como un pronombre de tercera persona, matizando el motivo -la historia y evolución de vuestra merced a usted-, con el objetivo de que entiendan por qué un pronombre de segunda persona concuerda con conjugación verbal de tercera.

En segundo lugar, la explicación del uso de vosotros/as tampoco resulta satisfactoria. Por una parte, la sustitución de vosotros/as por ustedes ya es bien sabido que no se halla solo en América Latina, sino también en Andalucía occidental y Canarias dentro del territorio de España. Por otra parte, según otro estudio que realizamos (Song, 2011), sobre la salida profesional de los alumnos chinos graduados en Filología Hispánica, una gran parte se incorpora a diversos Ministerios del Gobierno chino, empresas dirigidas por el gobierno con sucursales en todo el mundo y empresas multinacionales acreditadas en Hispanoamérica, así que parece imprescindible una introducción general acerca de los distintos sistemas pronominales de tratamiento en el mundo hispánico, en particular, el uso y la situación de vos, así como su paradigma verbal.

\subsection{Sugerencias y propuesta}

Teniendo en cuenta la propuesta de competencia comunicativa, planteada en el Marco común europeo de referencia para las lenguas (2002), que abarca tres subcompetencias, la lingüística, la sociolingüística y la pragmática, en la elaboración de manuales para el alumnado chino, hay que prestar atención a los siguientes aspectos relacionados con las FPT:

1. desde el punto de vista gramatical, propiedades como paradigma pronominal y verbal, regla de conjugación en cada país de habla hispana, presencia y ausencia de los pronombres sujeto, posición de los pronombres sujeto;

2. desde el punto de vista pragmático, propiedades como el concepto de cortesía, valores semánticos de los pronombres de tratamiento en cada comunidad;

3. desde el punto de vista sociocultural, los cuatro sistemas pronominales de tratamiento en el mundo hispánico, factores de la elección de los pronombres de tratamiento en determinados contextos comunicativos.

En nuestro caso, se pueden diseñar los siguientes tipos de ejercicios utilizando el corpus para cumplir con las necesidades socioculturales y pragmáticas por parte de los alumnos. Por un lado, se pueden extraer fragmentos conversacionales de un mismo ámbito en ambos idiomas y preparar archivos con la información de fondo expuesta, el antecedente, la situación comunicativa y la relación entre los personajes básicamente. En los ejercicios, se repasan los papeles preparados y se reproduce el vídeo sin sonido, para que el alumno deduzca, mediante la información proporcionada, las FPT que se usan. Los alumnos explican sus motivos de elección y el docente interviene y, al final, se reproduce el vídeo con sonido. Este tipo de ejercicios sirven para llamar la atención a los alumnos sobre la alternativa de $T / V$ en cada idioma y en cada ámbito, así como para que se fijen en el fenómeno de tratamiento simétrico/asimétrico. Por otro lado, 
se pueden reproducir los fragmentos más significativos, como los ejemplos arriba mostrados, con el propósito de que el alumnado reflexione qué significado tienen el $\mathrm{T}$ y el $V$ en cada idioma, comparando sus semejanzas y diferencias. Así pues, el alumnado adquiere, escuchando, pensando y observando, estas características socioculturales y pragmáticas progresivamente.

\section{CONCLUSIÓN}

Las formas pronominales de tratamiento, fenómeno lingüístico existente en todas las lenguas, suponen un campo interdisciplinario de investigación. En este trabajo, al revisar los estudios precedentes, se observa que hay ciertas polémicas sobre el fenómeno del tratamiento simétrico/asimétrico y los valores semánticopragmáticos de $T / V$. De este modo, a través de un corpus paralelo compilado a partir de dos teleseries españolas y una china, llegamos a la conclusión de que, en el plano sociocultural, cada sociedad muestra su preferencia por el uso de $T / V$ en distintos ámbitos; el tratamiento asimétrico aparece con mucha más frecuencia en chino que en español, puesto que el país asiático aún está experimentando cambios sociales hacia la igualdad. En el plano pragmático, los pronombres $T / V$, cuando se encuentran en el estado estático, poseen valores idénticos, mientras que en el estado dinámico, el $V$ puede representar en chino significados de cariño y acercamiento. Como se ha podido comprobar, toda esta información sociocultural y pragmática relacionada con el uso de las FPT no tiene el más mínimo reflejo en el manual de referencia de la E/LE más utilizado en China, lo que pone de relieve la necesidad de dar una orientación más comunicativa y contextualizada a esta enseñanza.

\section{BIBLIOGRAFÍA}

Aijón Oliva, M. Á. (2009): “Tú y usted como estrategias de estilo y persuasión en la comunicación publicitaria", Revista Electrónica de Estudios Filológicos, 18 [en línea], disponible en <http://www.um.es/tonosdigital/znum18/secciones/ estudio-1-tu_y_usted.htm> [consultado en marzo de 2015].

Alba De Diego, V. y Sánchez Lobato, J. (1980): “Tratamiento y juventud en la lengua hablada: aspectos sociolingüísticos", Boletín de la Real Academia Española, 60, 95 130.

Bestard Revilla, A. (2012): “Estudio sociolingüístico de las formas de tratamiento del habla coloquial de Santiago de Cuba", Boletín de Lingüística, 24, 28-53.

Blas Arroyo, J. L. (1994): “Los pronombres de tratamiento y la cortesía”, Revista de Filología, 13, 7-36.

Briz Gómez, A. (coord.) (1995), La conversación coloquial (Materiales para su estudio), Valencia: Universitat de València (Anejo XVI de la revista Cuadernos de Filología). 
Brown, R. y Gilman, A. (1960): “The pronouns of Power and Solidarity”, en T. A. Sebeok (ed.) (2005) Style in Language, Cambridge, MIT Press: 253-276.

Calderón Campos, M. (2010): “Capítulo 4. Formas de tratamiento", en M. Aleza Izquierdo y J. M. Enguita Utrilla (coords.) (2010) La lengua española en América: normas y usos actuales, Valencia, Universitat de València: 225-236.

Chen, S. C. (1983): “Alternativa de usted y tú en el habla pekinesa” [北京话 “您” “ 你” 使用规律初探], Filología china, 3, 18-25.

Dong, Y. Sh. y Liu, J. (1999): Español moderno (I/II) [现代西班牙语(一二)], Beijing, FLTP. Dong, Y.Sh. y Liu, J. (2000): Español moderno (III) [现代西班牙语(三)], Beijing, FLTP.

Dong, Y. Sh. y Liu, J. (2001): Español moderno (IV) [现代西班牙语(四)], Beijing, FLTP.

Dong, Y. Sh. y Liu, J. (2003): Español moderno (V) [现代西班牙语(五)], Beijing, FLTP.

Dong, Y. Sh. y Liu, J. (2007): Español moderno (VI) [现代西班牙语(六)], Beijing, FLTP.

Fernández, M. (2007): “Pronombres de segunda persona y fórmulas de tratamiento en español: una bibliografía", Lingüística en la Red, 4 [en línea], disponible en <http://www.linred.es/informacion_pdf/informacion13_06072006.pdf> [consultado en mayo de 2015].

García Godoy, M. T. (2010): “Fórmulas de tratamiento innovadoras en el español peninsular del siglo XIX", en B. K. Martin Hummel y M. E. Vásquez Laslop (eds.) (2010) Formas y fórmulas de tratamiento en el mundo hispánico, México, D. F., El Colegio de México: 595-618.

Jaime De Arrieta, S. y Cuadros De Béssega, M. (1997): “Variación de las formas de tratamiento pronominal en el español hablado en San Juan", en S. Jaime de Arrieta, M. Cuadros de Béssega, A. Romo de Merino, A. Jiménez de Martín, J. A. Berenguer y L. Berenguer de Strada (eds.) (1997) El lenguaje y su uso, San Juan, Servicio de publicaciones de la FFHA: 13-26.

Jang, J. S. (2010): “Fórmulas de tratamiento pronominales en los jóvenes universitarios de Medellín (Colombia) desde la óptica sociopragmática: estrato socioeconómico y sexo", Íkala, revista de lenguaje y cultura, 26, 43-116.

Kim,U. (2006): “Observaciones sobreel uso delas fórmulas de tratamiento pronominales en el español de Chile", Estudios Hispánicos, 41, 41-58.

Liu, Y. (2009): “El usted en el habla pekinesa” [北京话敬称代词 “您” 考源], Ciencias sociales de Pekín, 3, 24-33.

Lü, Sh. X. (1982): Pronombres personales del chino contemporáneo [近代汉语指代词], Pekín, Editorial Xuelin.

Martínez Gavilán, M. D. (1988): “Formas de tratamiento en el siglo XVII". Estudios humanísticos, Filología, 10, 85-105.

Medina López, J. (1991): Formas de tratamiento en Canarias: habla juvenil, Santa Cruz de Tenerife, Producciones Gráficas. 
Morín Rodríguez, A. (2001): Las formas pronominales de tratamiento en el español de Las Palmas de Gran Canaria: variación y actitudes lingüísticas, Granada, Método.

Morín Rodríguez, A. (2002): “Actitudes lingüísticas y formas pronominales de trato", en J. D. Luque Durán, A. Pamies Bertrán y F. J. Manjón Pozas (eds.) (2005) Actas del Congreso Internacional sobre Nuevas Tendencias de la Lingüística, Granada, Granada Lingüística: 571-580.

Paredes, F. (2010): “ ¿Es factible un cuestionario estándar para el estudio del tratamiento? La experiencia del proyecto PRESEEA en Madrid y Alcalá de Henares", en B. K. Martin Hummel y M. E. Vásquez Laslop (eds.) (2010) Formas y fórmulas de tratamiento en el mundo hispánico, México, D. F., El Colegio de México: 163-191.

Pedroviejo Esteruelas, J. M. (2006): “Un estudio sociolingüístico. Sistemas de tratamiento de la juventud de Valladolid", Tonos. Revista electrónica de estudios filológicos, 11 [en línea], disponible en <http://www.um.es/tonosdigital/ znum11/estudios/20-tratamiento.htm> [consultado en mayo de 2015].

Placencia, M. E. (2010): "El estudio de formas de tratamiento en Colombia y Ecuador", en B. K. Martin Hummel y M. E. Vásquez Laslop (eds.) (2010) Formas y fórmulas de tratamiento en el mundo hispánico, México, D. F., El Colegio de México:341-374.

Real Academia Española (2009): Nueva gramática de la lengua española (I), Madrid, Espasa.

Rigatuso, E. (2000): “Un aspecto de la pragmática de las fórmulas de tratamiento en español bonaerense", Revista Argentina de Lingüística, 16, 293-344.

Rodríguez Mendoza, J. (2003): Lenguaje y sociedad: la alternativa tú/usted en San Sebastián de La Gomera. [en línea], disponible en <ftp:/ / tesis.bbtk.ull.es/ccssyhum/cs150. pdf> [consultado en mayo de 2015].

Song, Y. (2010): “Formas pronominales de tratamiento en el español peninsular actual y en putonghua de China", RedELE, [en línea], disponible en <http://www. mecd.gob.es/redele/Biblioteca-Virtual/2010/ memoriaMaster/2-Semestre/ YangSong.html> [consultado en mayo de 2015].

Song, Y. (2011): Formas pronominales de tratamiento en español y chino. Orientaciones para su enseñanza en la clase de E/LE. Tesis doctoral, Universidad de León.

Song, Y.y Wang, J.W. (2014): "Hacia una nueva perspectiva de las formas de tratamiento pronominales. Un análisis a partir de dos teleseries", Estudios interlingüísticos, 2, 117-133.

Vila, R. (1987): “La segunda persona gramatical en función no deíctica”, Revista Española de Lingüística, 17, 57-68.

Xu, J. J. (2003): Deixis sociales de los pronombres personales en chino [现代汉语代词回指研 究], Pekín, Editorial de Ciencias Sociales.

Zhu, D. X. (1982): Apuntes de la gramática [语法讲义], Pekín, Editorial Comercial. 